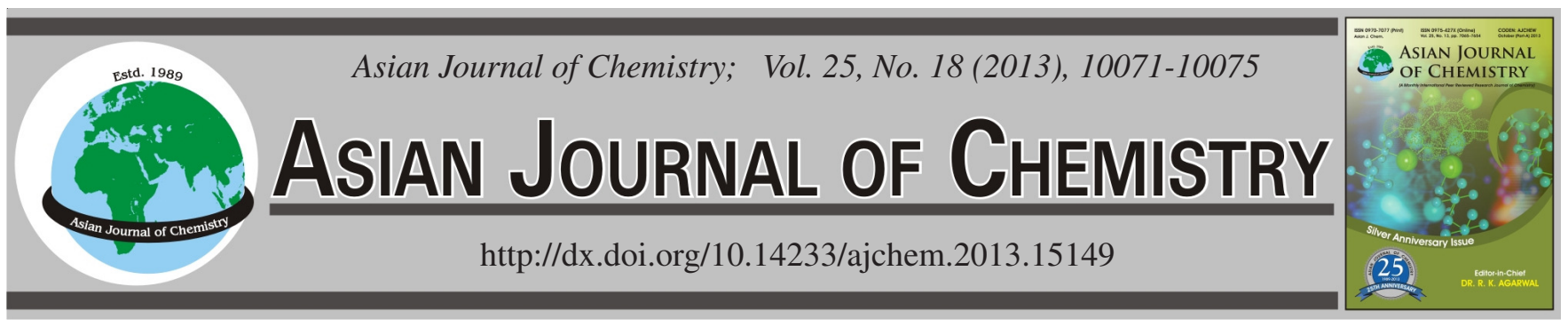

\title{
Fabrication and Applications of Amperometric Glucose Biosensor Based on CuO Nanowires/Graphene Modified Electrode
}

\author{
Liangliang Tian ${ }^{1}$, Yongyao Su $^{1, *}$ and Wenli LiaO ${ }^{2}$
}

\begin{abstract}
${ }^{1}$ Department of Research Center for Materials Interdisciplinary Science, Chongqing University of Arts and Sciences, Chongqing, P.R. China
\end{abstract} ${ }^{2}$ Department of Materials and Chemical Engineering Institute, Chongqing University of Arts and Sciences, Chongqing, P.R. China

*Corresponding author: E-mail: yongyaosu@ 126.com

(Received: 15 January 2013;

Accepted: 5 November 2013)

AJC-14337

\begin{abstract}
The copper(II) oxide nanowires (CuO NWs) synthesized by a simple method were applied to construct glucose amperometric biosensor. Graphene was also added to improve the performance of the sensor. The morphology and structure of $\mathrm{CuO}$ nanowires were investigated by SEM, TEM and XRD. The electrocatalytic oxidation of the $\mathrm{CuO}$ nanowires/graphene modified electrode towards glucose was studied by cyclic voltammetry and chronoamperometry. It is notable that the determination of the glucose has been achieved in enzyme-free conditions. The modified electrode presented excellent stability, reproducibility, high selectivity and quick response. The developed nonenzymatic biosensor exhibited excellent electroactivity towards glucose over a wide linear range of $1.6 \mu \mathrm{M}-6.0 \mathrm{mM}$ with a sensitivity of $375 \mu \mathrm{A} \mathrm{cm}{ }^{-2} \mathrm{mM}^{-1}$
\end{abstract}

Key Words: Glucose, CuO nanowire, Graphene, Amperometric biosensor.

\section{INTRODUCTION}

Glucose plays an important role in biosphere. Detection of glucose concentration is important for human health, food safety and biotechnology. Electrochemical sensor of glucose has attracted attentions in recent years because of the low cost, high sensitivity and quick response $\mathrm{e}^{1-3}$. Glucose oxidase $\left(\mathrm{GO}_{\mathrm{x}}\right)$ is widely used to built glucose amperometric sensor due to its high selectivity to glucose $e^{4-8}$. Despite high selectivity of $\mathrm{GO}_{\mathrm{x}}$ sensors, the enzymatic biosensors still suffer from the insufficient stability originated from the nature of the enzymes and the complexity of enzyme immobilization process ${ }^{9,10}$. Considering the above shortages of enzymatic biosensors, the study of enzyme-free glucose biosensors is aroused in this field. It is known that noble-metals show excellent electroactivity towards glucose. Therefore, various electrodes modified by noble-metals and their alloys have been studied, such as $\mathrm{Pd}^{11-13}$, $\mathrm{Pt}^{14-16}, \mathrm{Pt}^{-} \mathrm{Pd}^{17,18}, \mathrm{Au}^{19-21}, \mathrm{Au}-\mathrm{Cu}^{22}, \mathrm{Pt}-\mathrm{Au}^{23}$, etc. Higher stability of the glucose sensors was achieved by the application of noblemetals modified electrode. However, the noble-metals glucose amperometric sensors are high cost on account of the use of noble metals. The development of nonenzymatic glucose sensor with low cost, high sensitivity and selectivity is imperative.

Copper(II) oxide, a $p$-type semiconductor with a narrow band gap of $1.2 \mathrm{eV}$, has been widely used in semiconductors, gas sensors, catalysis and biosensors ${ }^{24,25}$. Some efforts have been made on amperometric determination of glucose using nanostructured $\mathrm{CuO}$. For instance, $\mathrm{CuO}$ nanocubes-graphene ${ }^{26}$, $\mathrm{CuO} /$ carbon nanotube ${ }^{27}, \mathrm{CuO} / \mathrm{GCE}^{28}$, etc. Copper(II) oxide nanowires have $1 \mathrm{D}$ electronic pathway, leading to efficient charge transport ${ }^{29}$. The space between neighboring nanowires is also favourable for the diffusion of electrolyte. Copper(II) oxide nanowires on a $\mathrm{Cu}$ rod were also synthesized for detection of glucose with high sensitivity ${ }^{9}$. However, the performance of the sensor may be affected because of the exposed active copper substrate. Graphene is an inexpensive material with excellent mechanical property, high electrical conductive property, large surface area and good biocompatibility ${ }^{30}$. Therefore, graphene is a potential matrix for electrochemical biosensors.

In this article, $\mathrm{CuO}$ nanowires were synthesized by a simple method ${ }^{31}$ with some modifications and then graphene was added to improve the performance of the biosensor. Electrochemical performance of the $\mathrm{CuO}$ nanowires/graphene modified electrode was measured by cyclic voltammetry and chronoamperometry. It is revealed that the $\mathrm{CuO}$ nanowires/ graphene modified electrode showed high sensitivity, stability and quick response, indicating the potential application in the field of glucose sensor.

\section{EXPERIMENTAL}

$\mathrm{D}(+)$-Glucose, L-ascorbic acid (AA), uric acid (UA), dopamine (DA) and nafion solution (5 wt \% in lower aliphatic 
alcohol and water mixture) were purchased from Sigma (USA). All other reagents were of analytical grade and used as received without further purification (Chengdu Kelong). High quality deionized water (resistivity $>18.0 \mathrm{M} \Omega \mathrm{cm}^{-1}$ ) used for all experiments was prepared by a Water Purification System (UPT-II-10T) provided by Chengdu YouPu.

Detection method: All electrochemical measurements were performed on a Potentiostat/Galvanostat Model 263 electrochemical workstation (Ametek, USA). A conventional three electrode system was used with a saturated $\mathrm{Ag} / \mathrm{AgCl}$ as the reference electrode, a platinum electrode $(\Phi=3 \mathrm{~mm})$ as the counter electrode and a modified GCE $(\Omega=3 \mathrm{~mm}, \mathrm{CHI} 105)$ as the working electrode. X-Ray diffraction (XRD) measurements were performed on a Rigaku D/Max-2400 X-ray diffractometer using $\mathrm{CuK}_{\alpha}$ radiation $(40 \mathrm{kV}, 60 \mathrm{~mA})$. The morphology was analyzed on a Hitachi S-4800 field emission scanning electron microscope (FESEM).

General procedure: Graphene was synthesized according to the previous report ${ }^{32,33}$. First, graphite powders were preoxidized in a mixture of $\mathrm{H}_{2} \mathrm{SO}_{4}, \mathrm{~K}_{2} \mathrm{~S}_{2} \mathrm{O}_{8}$ and $\mathrm{P}_{2} \mathrm{O}_{5}$. The preoxidized graphite was then reoxidized by the Hummers and Offeman method. Exfoliation was carried out by sonicating $2.5 \mathrm{mg} / \mathrm{mL}$ graphite oxide dispersion under ambient conditions for $1 \mathrm{~h}$. $5 \mathrm{~g} \mathrm{NaBH}_{4}$ was dissolved into $200 \mathrm{~mL}$ graphite oxide solution at $80{ }^{\circ} \mathrm{C}$ under stirring. After $2 \mathrm{~h}$, the black products were filtered and dried.

$\mathrm{CuO}$ nanowires were synthesized by a reported simple method with some modifications ${ }^{31}$. In a typical procedure, $0.7 \mathrm{~g}$ $\mathrm{Cu}(\mathrm{OAc})_{2} \cdot \mathrm{H}_{2} \mathrm{O}$ was directly transferred into $50 \mathrm{~mL} 0.1 \mathrm{M}$ $\mathrm{NaOH}$ under magnetic stirring at $25^{\circ} \mathrm{C}$. After $8 \mathrm{~h}$, the obtained black products were separated and washed by water for several times.

$\mathrm{CuO}$ nanowires/graphene modified GCE $(\Phi=3 \mathrm{~mm})$ was used as working electrode. First, the GCE was carefully polished with $0.05 \mu \mathrm{m}$ alumina powder. Then, the polished GCE was cleaned by $\mathrm{HNO}_{3}(1: 1)$, alcohol and water under ultrasound. The synthesized $\mathrm{CuO}$ nanowires were transferred into alcohol to form a $8 \mathrm{mg} / \mathrm{mL}$ dispersion. Graphene was added to 0.2 wt $\%$ chitosan solution under sonication to make a $1 \mathrm{mg} / \mathrm{mL}$ dispersion. $1 \mathrm{~mL}$ of the graphene dispersion was mixed with $1 \mathrm{~mL}$ of the $\mathrm{CuO}$ nanowires dispersion under sonication to form a homogeneous dispersion. Alcohol was used to adjust the surface tension. Then $4 \mu \mathrm{L}$ (containing $2 \mu \mathrm{g}$ graphene and $16 \mu \mathrm{g} \mathrm{CuO}$ nanowires) of the mixture was casted onto the pretreated GCE and the modified GCE was dried for $12 \mathrm{~h}$ in air. Finally, $4 \mu \mathrm{L}$ of $0.5 \mathrm{wt} \%$ nafion solution was added to protect the modified electrode.

\section{RESULTS AND DISCUSSION}

Characterization: Morphology and structure of the $\mathrm{CuO}$ nanowires and graphene were investigated by SEM, TEM and $\mathrm{XRD}$ and the results were showed in Fig. 1. Obviously, $\mathrm{CuO}$ nanowires were successfully synthesized by the simple method. It is characterized that the $\mathrm{CuO}$ nanowires were $30-50 \mathrm{~nm}$ wide in diameter and 1-3 $\mu \mathrm{m}$ long in length (Fig. 1a). The $\mathrm{CuO}$ nanowires had large surface area, which benefitted the electrocatalytic oxidation of glucose. As can be seen from Fig. 1b, all the diffraction peaks can be indexed to monoclinic
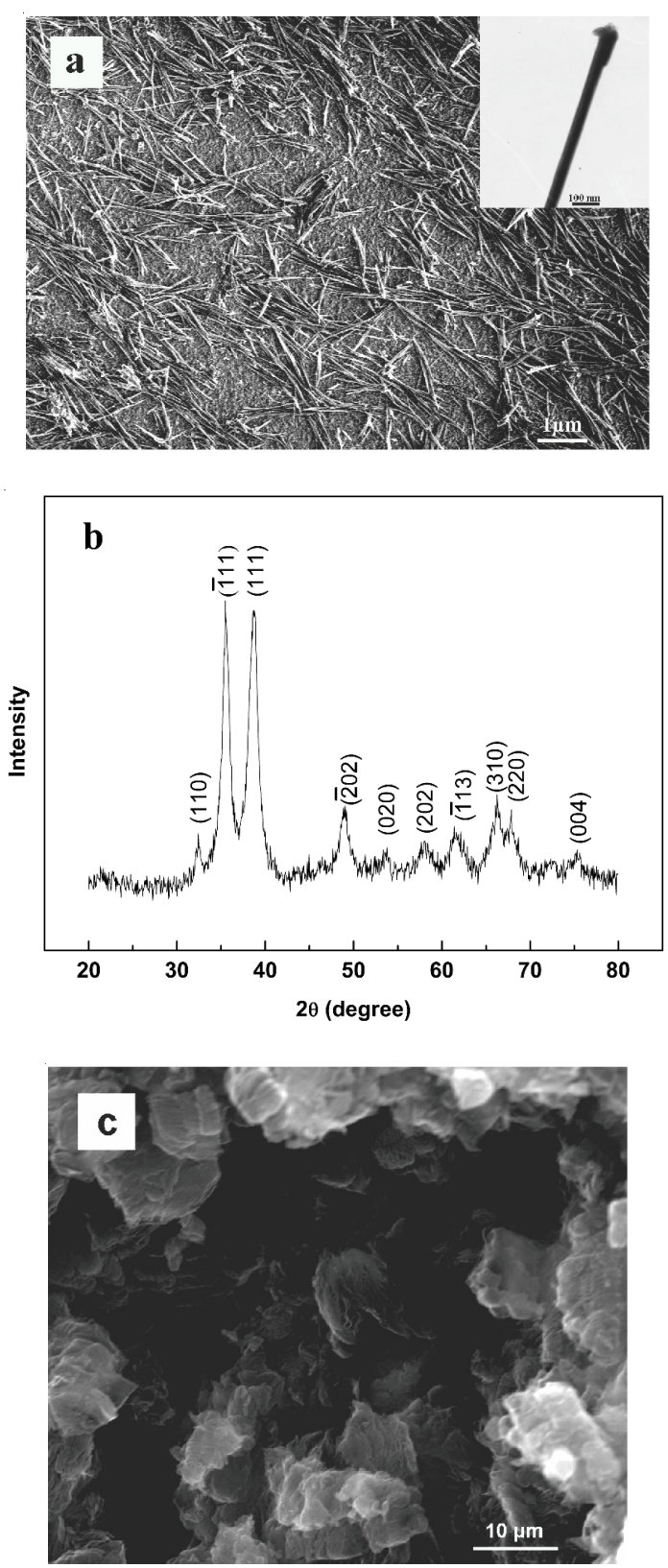

Fig. 1. (a) SEM image of the obtained $\mathrm{CuO}$ nanowires on $\mathrm{Cu}$ substrate; Inset is the TEM image of a single $\mathrm{CuO}$ nanowire; (b) XRD pattern of the $\mathrm{CuO}$ nanowires. (c) SEM image of the synthesized graphene

phase $\mathrm{CuO}$ (JCPDS card No. 41-0254), which was consistent with the reported articles ${ }^{34,35}$. Fig. 1c was the SEM image of the as-prepared graphene sheets. The graphene sheets were $5-10 \mu \mathrm{m}$ in diameter.

Optimal experiment condition: In order to obtain the optimal response to glucose, the effects of applied potential and $\mathrm{NaOH}$ concentration on the response current towards 0.1 $\mathrm{mM}$ glucose were investigated (Fig. 2). As can be seen from Fig. 2a, the response current achieved maximum value at $\mathrm{NaOH}$ concentration $0.1 \mathrm{M}$. The results agreed with the previous report ${ }^{36}$. From Fig. 2b, the response current increased with the increase of the applied potential from 0.4-0.7 V. Optimal amperometric current response with better linear relation was obtained at potential $0.6 \mathrm{~V}$. Therefore, $0.1 \mathrm{M} \mathrm{NaOH}$ was chosen as the support electrolyte and $0.6 \mathrm{~V}$ was chosen as the applied potential. 

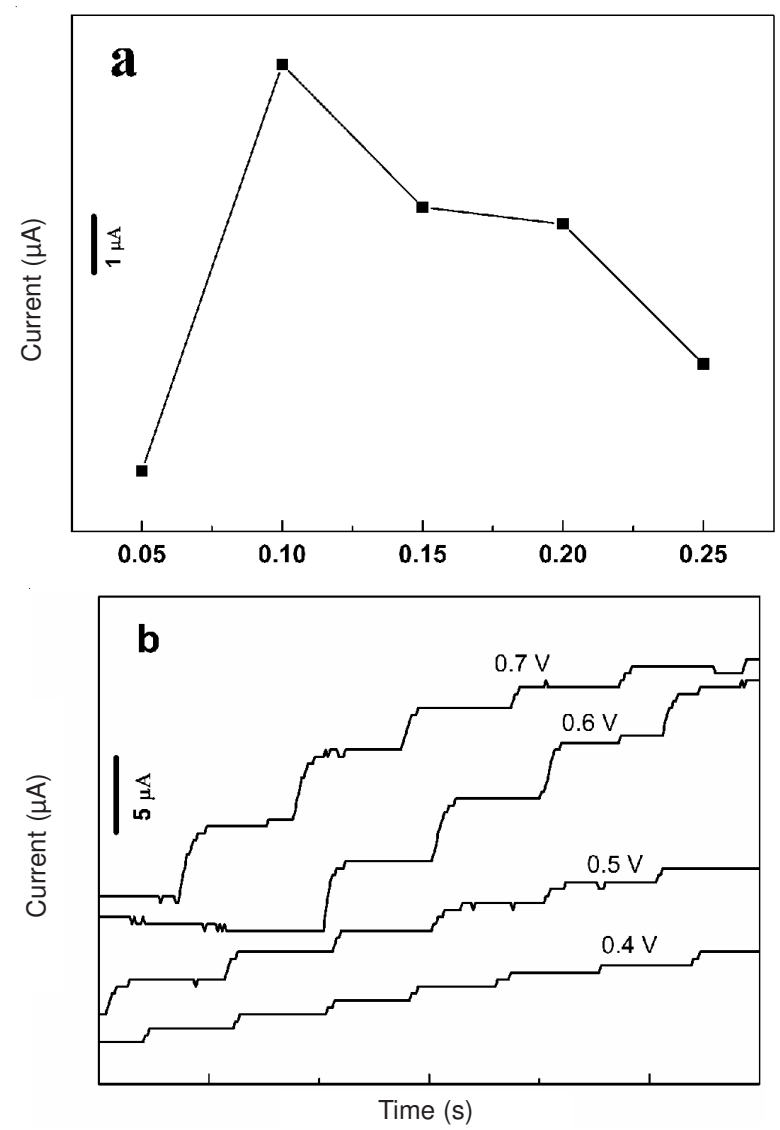

Fig. 2. Effects of applied potential (a) and $\mathrm{NaOH}$ concentration (b) on the response current of the $\mathrm{CuO}$ nanowires/graphene modified electrode towards $0.1 \mathrm{mM}$ glucose

Electrooxidation of glucose at $\mathrm{CuO}$ nanowires/ graphene modified electrode: Fig. 3 showed cyclovoltammograms of the bare GCE (a) and chitosan (b), graphene (c), $\mathrm{CuO}$ nanowires (d), graphene/CuO nanowires (e) modified GCE in $0.1 \mathrm{M} \mathrm{NaOH}$. After the electrode was modified with chitosan (curve b), lower current was observed compared with the bare GCE (curve a) due to the chitosan membrane hindering the diffusion of electrons towards the GCE surface. An increase in peak current and well-defined cyclovoltammogram curve was observed when graphene was covered onto the electrode (curve c) because of the excellent conductivity of graphene. After $\mathrm{CuO}$ nanowires were anchored onto the GCE, the current significantly increased (curve d). This could be attributed to the great enhancement of the active area of the surface. The current further increased again (curve e) when both the $\mathrm{CuO}$ nanowires and graphene were added. This can be ascribed to the excellent conductivity of graphene and larger active surface of $\mathrm{CuO}$ nanowires.

Fig. 4a displayed the cyclovoltammograms of $\mathrm{CuO}$ nanowires/graphene modified electrode in $0.1 \mathrm{M} \mathrm{NaOH}$ with 0-3.0 $\mathrm{mM}$ of glucose. It is found that the response current at $0.6 \mathrm{~V}$ apparently increased when the glucose was added, indicating that the modified electrode showed excellent electrocatalytic activity to glucose. It is reported that glucose was oxidized by $\mathrm{Cu}(\mathrm{I}), \mathrm{Cu}(\mathrm{II})$ and $\mathrm{Cu}(\mathrm{III})$ surface states followed by adsorption onto the electrode surface. The oxidation potential of $\mathrm{Cu}(\mathrm{II})$ to $\mathrm{Cu}$ (III) was between 0.4 and $0.8 \mathrm{~V}$. When glucose oxidation occurred in the potential range of $0.40-0.8 \mathrm{~V}, \mathrm{Cu}$ (III) species

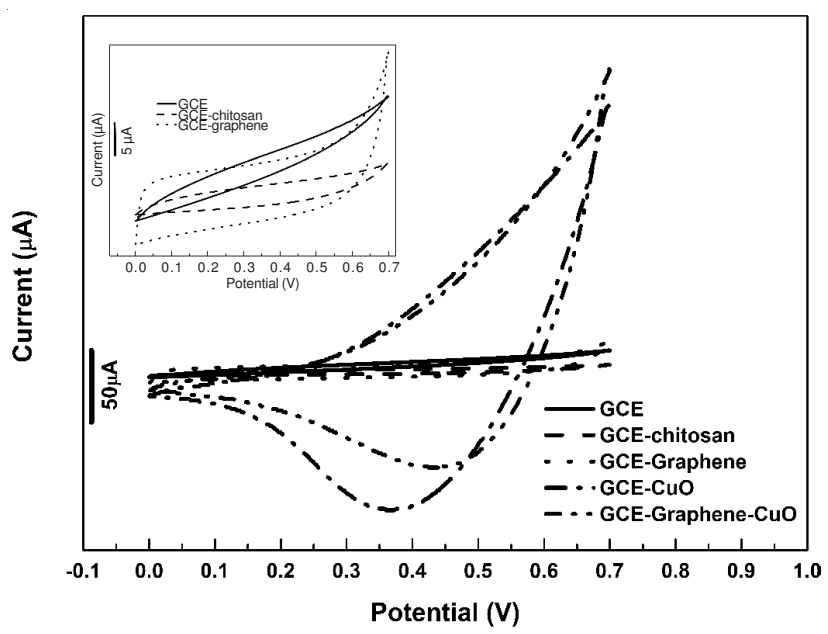

Fig. 3. Cyclic voltammograms of bare GCE (a), GCE-chitosan (b), GCE-graphene (c), GCE-CuO nanowires (d), GCE-graphene-CuO nanowires (e) in $0.1 \mathrm{M} \mathrm{NaOH}$ without stirring. Scan rate: $50 \mathrm{mv} \mathrm{s}^{-1}$

were proposed to act as an electron transfer mediator ${ }^{37}$. Moreover, with the further increase of glucose concentration, the response current linearly increased. As can be seen from Fig. $4 \mathrm{~b}$, the catalytic current of $\mathrm{CuO}$ nanowires/graphene modified electrode exhibited a linear dependence on glucose concentration from $0-3 \mathrm{mM}$ with an equation $\mathrm{I}_{\mathrm{pc}}=0.0267 \mathrm{x}+119.71$ $\left[\mathrm{I}_{\mathrm{pc}}(\mu \mathrm{A}) ; \mathrm{x}(\mu \mathrm{M}) ; \mathrm{R}=0.9997\right]$.
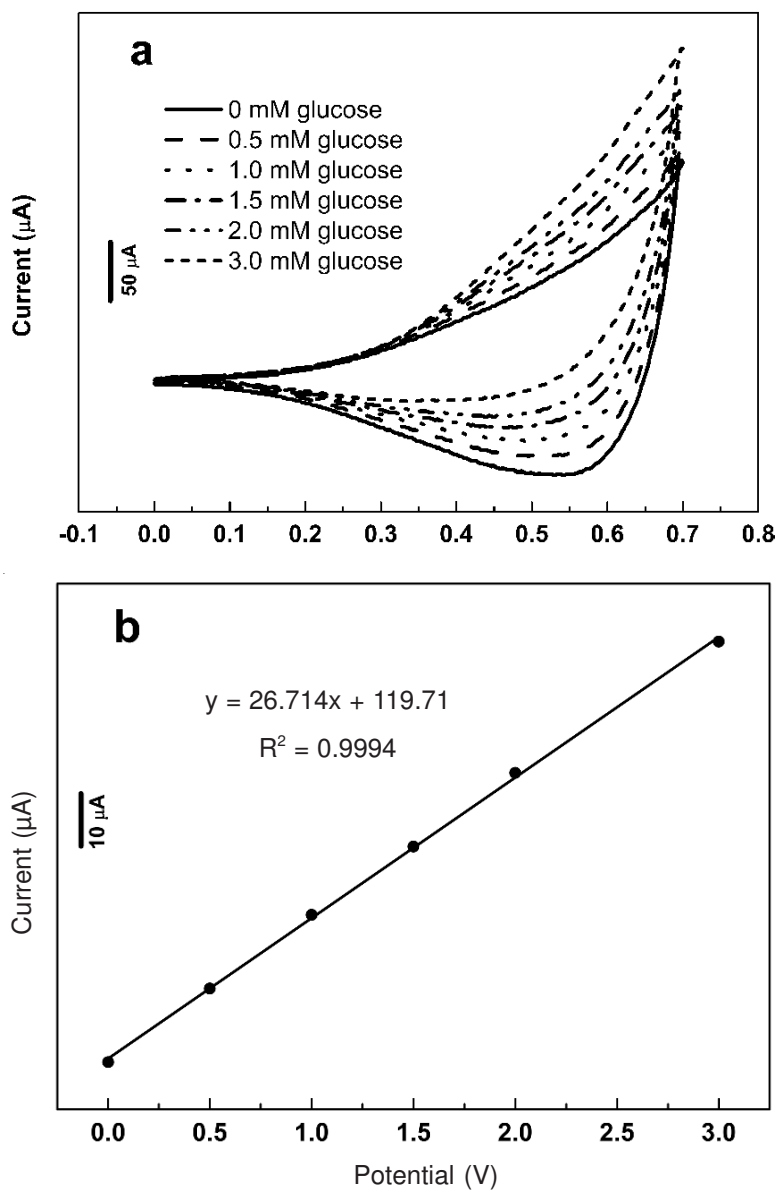

Fig. 4. (a) Cyclic voltammograms of $\mathrm{CuO}$ nanowires/graphene modified electrode in $0.1 \mathrm{M} \mathrm{NaOH}$ containing different concentration of glucose. Scan rate: $50 \mathrm{mv} \mathrm{s}^{-1}$. (b) The relationship between response current and the concentration of glucose 


\section{Amperometric performance of the $\mathrm{CuO}$ nanowires/ graphene/GCE to glucose}

Amperometric analysis: The amperometric response of the $\mathrm{CuO}$ nanowires/graphene modified electrode at a constant potential of $0.6 \mathrm{~V}$ to successive addition of $0.5 \mathrm{mM}$ glucose in $0.1 \mathrm{M} \mathrm{NaOH}$ was displayed in Fig 5. After $0.5 \mathrm{mM}$ glucose was successively added into the stirred $0.1 \mathrm{M} \mathrm{NaOH}$, the oxidation current of $\mathrm{CuO}$ nanowires/graphene modified electrode was enhanced at a fixed step. From the top left inset, the same performance was also investigated at low glucose concentration after $0.1 \mathrm{mM}$ glucose was successively added. As can be seen from the bottom right inset, the linear relationship between the oxidation current and the glucose concentration was obtained for concentration ranging from $1.6 \mu \mathrm{M}$ to $6 \mathrm{mM}$. The linear regression equation was given by $I_{p c}=0.0265 x+42.583\left[I_{p c}\right.$ $(\mu \mathrm{A}) ; \mathrm{x}(\mu \mathrm{M}) ;$, with a correlation coefficient of $\mathrm{R}=0.9972$. The detection limit of glucose using a $\mathrm{CuO}$ nanowires/ graphene modified electrode was found to be $1.6 \mu \mathrm{M}$ with the sensitivity of $375 \mu \mathrm{A} \mathrm{cm} \mathrm{cm}^{-1}$. The sensitivity was higher than that of $\mathrm{CuO}$ nanorod/graphite $\left(371 \mu \mathrm{A} \mathrm{cm}^{-2} \mathrm{mM}^{-1}\right)^{38}, \mathrm{CuO}$ nanofibers $/ \mathrm{TiO}_{2}$ nanotube $\left(80 \mu \mathrm{A} \mathrm{cm}^{-2} \mathrm{mM}^{-1}\right)^{34}, \mathrm{Cu} / \mathrm{MCNT} /$ $\operatorname{GCE}\left(251.38 \mu \mathrm{A} \mathrm{cm}^{-2} \mathrm{mM}^{-1}\right)^{37}, \mathrm{Pt}-\mathrm{Pb} / \mathrm{MWCNT}\left(17.8 \mu \mathrm{A} \mathrm{cm} \mathrm{cm}^{-2}\right.$ $\left.\mathrm{mM}^{-1}\right)^{39}, \mathrm{Co}_{3} \mathrm{O}_{4} \mathrm{NFs} /$ nafion $\left(36.25 \mu \mathrm{A} \mathrm{cm}^{-2} \mathrm{mM}^{-1}\right)^{40}$, etc.

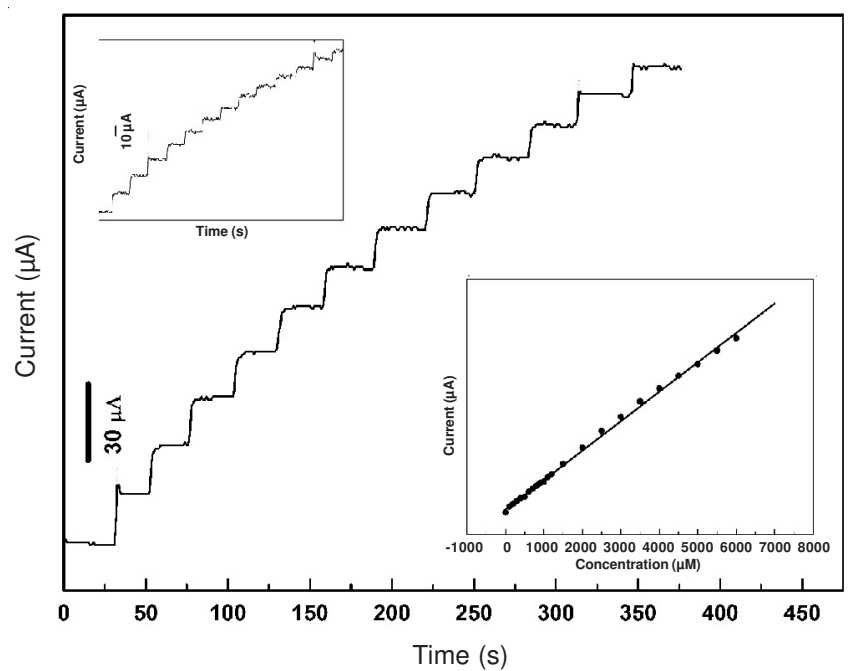

Fig. 5. Typical current-time response curve of $\mathrm{CuO}$ nanowires/graphene modified electrode towards $0.5 \mathrm{mM}$ glucose at $0.6 \mathrm{~V}$. (Inset at the top left corner is the current-time response towards $0.1 \mathrm{mM}$ glucose at $0.6 \mathrm{~V}$ between 0 and $1.2 \mathrm{mM}$; Inset at bottom right corner is the relationship of catalytic current and the concentration of glucose)

Stability, selectivity and reproducibility: The stability of the $\mathrm{CuO}$ nanowires/graphene/GCE was investigated by measuring its sensitivity towards $1 \mathrm{mM}$ glucose over 10 days under ambient conditions. It is found that the sensor still retained $89.5 \%$ of its original sensitivity after ten days, which showed excellent long-term stability at room temperature. The current response of $\mathrm{CuO}$ nanowires/graphene/GCE was stable over a long operational period of $2000 \mathrm{~s}$ for $1 \mathrm{mM}$ glucose in $0.1 \mathrm{M}$ $\mathrm{NaOH}$ with a loss of $3.69 \%$ of its original current response. From the inset of Fig. 6, the response time of the $\mathrm{CuO}$ nanowires/ graphene modified electrode towards $1 \mathrm{mM}$ glucose was about $4 \mathrm{~s}$, which was shorter than that of $\mathrm{CuO}$ nanorod/graphite (10 $\mathrm{s})^{38}, \mathrm{Pt}-\mathrm{Pb} / \mathrm{MWCNT}(12 \mathrm{~s})^{39}, \mathrm{Co}_{3} \mathrm{O}_{4}$ nanoflowers/nafion $(7 \mathrm{~s})^{40}$,
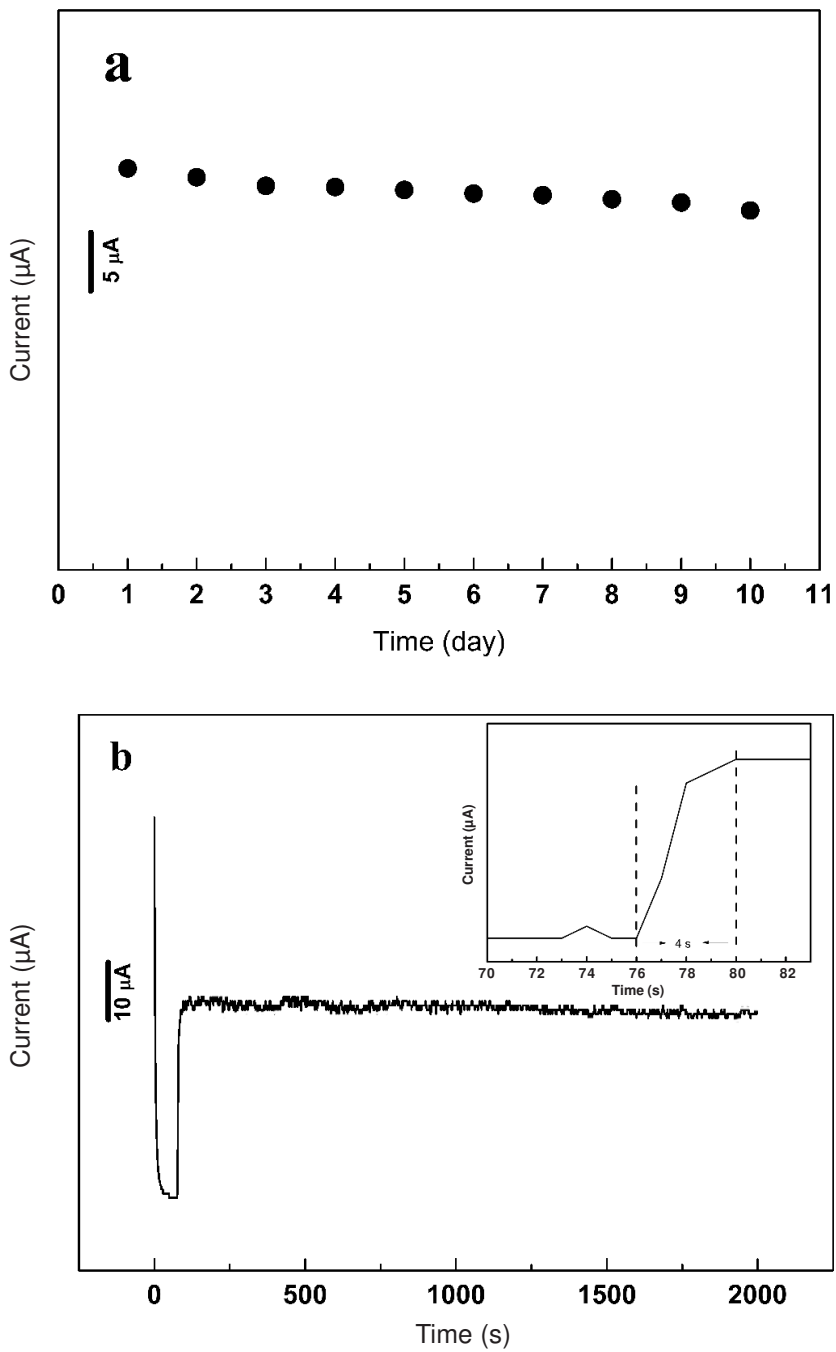

Fig. 6. Amperometric response towards $0.1 \mathrm{mM}$ glucose running for $2000 \mathrm{~s}$. Inset is the illustration of response time

$\mathrm{GE} / \mathrm{CuO} / \mathrm{GOx} / \mathrm{Nafion}(5 \mathrm{~s})^{41}, \mathrm{CuO}$ flowers/G $(15 \mathrm{~s})^{34}$, etc. On the basis of above discussion, the $\mathrm{CuO}$ nanowires/graphene modified electrode presented high sensitivity, stability and quick response. The high sensitivity of the modified electrode can be attributed to two factors. First, $\mathrm{CuO}$ nanowires and graphene both had larger activity area. On the other hand, graphene possessed excellent electrical conductive property ${ }^{30}$.

One of the most important analytical factors for an amperometric biosensor was the ability to separate the interfering species from the target analyte. In the case of glucose, ascorbic acid (AA), uric acid (UA), dopamine (DA) present in physiological environment were the most important interferences for direct electrochemical oxidation of glucose. We studied selectivity of the $\mathrm{CuO}$ nanowires/graphene/GCE by adding $0.1 \mathrm{mM}$ ascorbic acid, uric acid and dopamine into $1 \mathrm{mM}$ glucose during the test of chronoamperometry and the results were listed in Fig. 7. For all the interfering species tested in $0.1 \mathrm{M} \mathrm{NaOH}, \mathrm{CuO}$ nanowires/graphene/GCE did not show significant change in the sensor responses and the current responses due to the added interfering species were only 2.8 $5.7 \%$ as that of glucose.

In order to prove its reliability, the sensor was used to measure the glucose concentration in human serum. $80 \mu \mathrm{L}$ of 


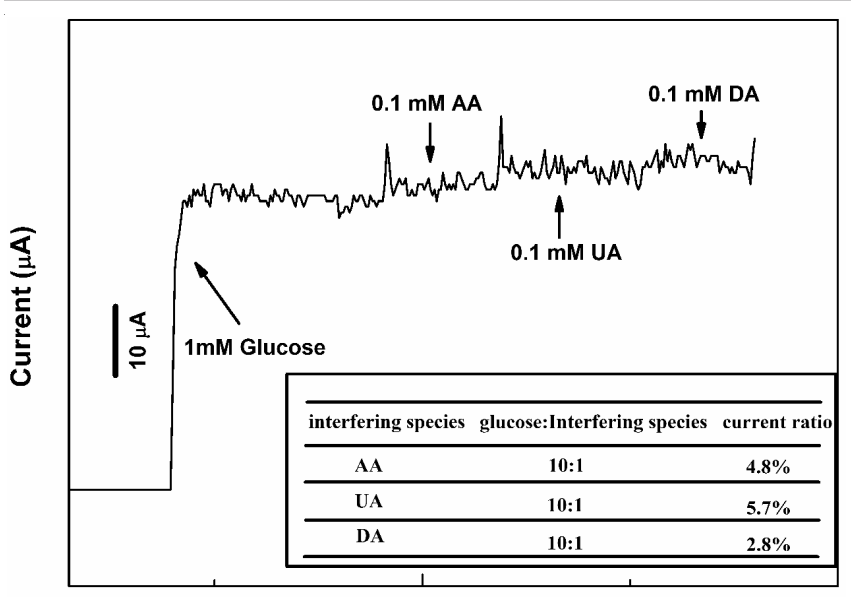

Time (S)

Fig. 7. Interferences of ascorbic acid, uric acid and dopamine to glucose oxidation on the $\mathrm{CuO}$ nanowires/graphene modified electrode

serum was added into $40 \mathrm{~mL} 0.1 \mathrm{M} \mathrm{NaOH}$ electrolyte at $0.6 \mathrm{~V}$ under stirring. $0.1 \mathrm{mM}$ pure glucose was added into the electrolyte to test the recovery. All the results were listed in Table- 1 . It is clear that the recovery was both higher than $95 \%$, revealing a potential application in glucose sensor.

\begin{tabular}{cccccc}
\multicolumn{7}{c}{ TABLE-1 } \\
\multicolumn{7}{c}{ DETERMINATION OF GLUCOSE IN } \\
HUMAN BLOOD SERUM SAMPLS \\
Sample & $\begin{array}{c}\text { Glc conc. } \\
(\mathrm{mM})\end{array}$ & $\begin{array}{c}\text { Found } \\
(\mathrm{mM})\end{array}$ & $\begin{array}{c}\text { RSD }(\%) \\
(\mathrm{n}=3)\end{array}$ & $\begin{array}{c}\text { Added } \\
(\mathrm{mM})\end{array}$ & $\begin{array}{c}\text { Recovery } \\
(\%)\end{array}$ \\
\hline 1 & 4.5 & 4.41 & 3.8 & 0.1 & 95.7 \\
2 & 5.2 & 5.08 & 2.7 & 0.1 & 97.3 \\
\hline
\end{tabular}

\section{Conclusion}

Copper(II) oxide nanowires were successfully synthesized by a simple method. Then the $\mathrm{CuO}$ nanowires were used to construct glucose amperometric sensor. Simultaneously, graphene was added to improve the sensitivity of the sensor. The prepared glucose sensor presented high sensitivity, long term stability and shorter response time. In conclusion, the $\mathrm{CuO}$ nanowires/graphene modified electrode can be used as an amperometric sensor for practical analysis of glucose in real blood serum samples.

\section{ACKNOWLEDGEMENTS}

This research was supported by the Foundation of Chongqing Education Commission (KJ121213) and Talent Introduction Foundation of Chongqing University of arts and sciences (R2012c114).

\section{REFERENCES}

1. Y. Lin, F. Lu, Y. Tu and Z. Ren, Nano Lett., 4, 191 (2004).

2. J. Wang, Electroanalysis, 17, 7 (2005).

3. J. Wang, Chem. Rev., 108, 814 (2008).
4. X. Luo, J. Xu, Y. Du and H.-Y. Chen, Anal. Biochem., 334, 284 (2004).

5. H. Zhang, Z. Meng, Q. Wang and J. Zheng, Sens. Actuators B, 158, 23 (2011).

6. U. Prüße, M. Herrmann, C. Baatz and N. Decker, Appl. Catal. A Gen., 406, 89 (2011).

7. B. Unnikrishnan, S. Palanisamy and S. Chen, Biosens. Bioelectron., 39, 70 (2013).

8. C. Shan, H. Yang, D. Han, Q. Zhang, A. Ivaska and L. Niu, Biosens. Bioelectron., 25, 1070 (2010).

9. Z. Zhuang, X. Su, H. Yuan, Q. Sun, D. Xiao and M.M.F. Choi, Analyst, 133, 126 (2007).

10. S. Li, Ya. Zheng, G.W. Qin, Y. Ren, W. Pei and L. Zuo, Talanta, 85, 1260 (2011).

11. R. O'Neill, S. Chang, J.P. Lowry and C.J. McNeil, Biosens. Bioelectron., 19, 1521 (2004).

12. X. Chen, H. Pan, H. Liu and M. Du, Electrochim. Acta, 56, 636 (2010).

13. A. Gutés, C. Carraro and R. Maboudian, Electrochim. Acta, 56, 5855 (2011).

14. M. Guo, H. Hong, X. Tang, H. Fang and X. Xu, Electrochim. Acta, 63, 1 (2012).

15. M. Yang, Y. Yang, Y. Liu, G. Shen and R. Yu, Biosens. Bioelectron., 21, 1125 (2006).

16. Y. Ding, Y. Liu, L. Zhang, Y. Wang, M. Bellagamba, J. Parisi, C. Li and Y. Lei, Electrochim. Acta, 58, 209 (2011).

17. X. Niu, M. Lan, C. Chen and H. Zhao, Talanta, 99, 1062 (2012).

18. X. Bo, J. Bai, L. Yang and L. Guo, Sens. Actuators B, 157, 662 (2011).

19. B. Zheng, S. Xie, L. Qian, H. Yuan, D. Xiao and M. Choi, Sens. Actuators $B, 152,49$ (2011).

20. Y. Bai, H. Yang, W. Yang, Y. Li and C. Sun, Sens. Actuators B, 124, 179 (2007).

21. S. Cherevko and C. Chung, Sens. Actuators B, 142, 216 (2009).

22. D. Liu, Q. Luo and F. Zhou, Synth. Met., 160, 1745 (2010).

23. F. Xiao, Y. Li, H. Gao, S. Ge and H. Duan, Biosens. Bioelectron., 41, 417 (2013).

24. J. Zhang, J. Liu, Q. Peng, X. Wang and Y. Li, Chem. Mater., 18, 867 (2006).

25. S. Anandan, X. Wen and S. Yang, Mater. Chem. Phys., 93, 35 (2005).

26. L. Luo, L. Zhu and Z. Wang, Bioelectrochemistry, 88, 156 (2012).

27. J. Zheng, Q. Zhang, X. He, M. Gao, X. Ma and G. Li, Proced. Eng., 36, 235 (2012).

28. W.-Z. Le and Y.-Q. Liu, Sens. Actuators B, 141, 147 (2009).

29. Y. Li, X. Lv and J. Li, Appl. Phys. Lett., 95, 113102 (2009).

30. K.S. Novoselov, Science, 306, 666 (2004).

31. X. Wang, Tsinghua University, Beijing, p. 111 (2004).

32. Y. Wang, Y. Shao, D. Matson, J. Li and Y. Lin, ACS Nano, 4, 1790 (2010).

33. H. Shin, K. Kim, A. Benayad, S. Yoon, H.K. Park, I.-S. Jung, M.H. Jin, H.-K. Jeong, J.M. Kim, J.-Y. Choi and Y.H. Lee, Adv. Funct. Mater., 19, 1987 (2009).

34. S. Luo, F. Su, C. Liu, J. Li, R. Liu, Y. Xiao, Y. Li, X. Liu and Q. Cai, Talanta, 86, 157 (2011).

35. F. Ke, L. Huang, G. Wei, L. Xue, J. Li, B. Zhang, S. Chen, X. Fan and S. Sun, Electrochim. Acta, 54, 5825 (2009).

36. L. Lu, X. Zhang, G. Shen and R. Yu, Anal. Chim. Acta, 715, 99 (2012).

37. X. Kang, Z. Mai, X. Zou, P. Cai and J. Mo, Anal. Biochem., 363, 143 (2007).

38. X. Wang, C. Hu, H. Liu, G. Du, X. He and Y. Xi, Sens. Actuators B, 144, 220 (2010).

39. H. Cui, J. Ye, W. Zhang, C. Li, J.H.T. Luong and F.-S. Sheu, Anal. Chim. Acta, 594, 175 (2007).

40. Y. Ding, Y. Wang, L. Su, M. Bellagamba, H. Zhang and Y. Lei, Biosens. Bioelectron., 26, 542 (2010).

41. A. Umar, M. Rahman, A. Al-Hajry and Y. Hahn, Electrochem. Commun., 11, 278 (2009). 